\title{
Design guidelines for FRP reinforced concrete structures
}

Kypros Pilakoutas PhD, DEng

Professor of Construction Innovation, Centre for Cement and Concrete, Department of Civil and Structural Engineering, University of Sheffield, Sheffield, UK

Maurizio Guadagnini Dott Ing, PhD

Lecturer, Centre for Cement and Concrete, Department of Civil and Structural Engineering, University of Sheffield, Sheffield, UK
Kyriacos Neocleous PhD

Senior Research Fellow, Centre for Cement and Concrete, Department of Civil and Structural Engineering, University of Sheffield, Sheffield, UK

Stijn Matthys Ir, PhD

Professor, Magnel Laboratory for Concrete Research, Faculty of Engineering, University of Ghent, Ghent, Belgium

This paper presents an outline of the approach proposed by fib task group 9.3 for the next generation of design guidelines for fibre-reinforced polymer (FRP) reinforced concrete structures. The approach covers a range of FRPrelated topics, including material properties, durability, design philosophy, the limit states of bending, shear, cracking and deflection, and bond.

\section{Notation}

$A_{\mathrm{f}} \quad$ area of longitudinal reinforcement

$A_{\text {fmin }}$ minimum limit for area of longitudinal reinforcement

$b \quad$ width (mm)

$d \quad$ effective depth (mm)

$d_{\mathrm{b}} \quad$ diameter of shear reinforcement (mm)

$E_{\mathrm{f}} \quad$ static modulus of elasticity of longitudinal reinforcement $\left(\mathrm{N} / \mathrm{mm}^{2}\right)$

$E_{\mathrm{fk}} \quad$ characteristic value of static modulus of elasticity of longitudinal reinforcement $\left(\mathrm{N} / \mathrm{mm}^{2}\right)$

$F_{\mathrm{C}} \quad$ compression force developed in concrete (N)

$F_{\mathrm{T}} \quad$ tensile force developed in an FRP bar (N)

$f_{\mathrm{C}} \quad$ concrete cylinder compressive stress $\left(\mathrm{N} / \mathrm{mm}^{2}\right)$

$f_{\mathrm{c}}^{\prime} \quad$ concrete cylinder compressive strength $\left(\mathrm{N} / \mathrm{mm}^{2}\right)$

$f_{\text {cd }}$ design value of concrete cylinder compressive strength $\left(\mathrm{N} / \mathrm{mm}^{2}\right)$

$f_{\mathrm{ck}} \quad$ characteristic value of concrete cylinder compressive strength $\left(\mathrm{N} / \mathrm{mm}^{2}\right)$

$f_{\mathrm{ctm}} \quad$ average value of concrete tensile strength $\left(\mathrm{N} / \mathrm{mm}^{2}\right)$

$f_{\mathrm{fb}} \quad$ tensile strength of bent portion of shear reinforcement $\left(\mathrm{N} / \mathrm{mm}^{2}\right)$

$f_{\mathrm{fk}} \quad$ characteristic value of ultimate tensile strength of longitudinal reinforcement $\left(\mathrm{N} / \mathrm{mm}^{2}\right)$

$f_{\text {fu }} \quad$ ultimate tensile strength of longitudinal FRP reinforcement $\left(\mathrm{N} / \mathrm{mm}^{2}\right)$

$f_{\mathrm{fw}} \quad$ maximum allowable stress to be developed in the shear links $\left(\mathrm{N} / \mathrm{mm}^{2}\right)$

$M_{\mathrm{u}} \quad$ ultimate moment of resistance (Nmm)

$r_{\mathrm{b}} \quad$ bend radius of shear reinforcement $(\mathrm{mm})$

$x \quad$ neutral axis depth ( $\mathrm{mm})$

$x_{\mathrm{FRP}} \quad$ neutral axis depth of concrete section reinforced with FRP reinforcement $(\mathrm{mm})$

$x_{\text {steel }} \quad$ neutral axis depth of concrete section reinforced with steel reinforcement $(\mathrm{mm})$

$\alpha_{\mathrm{cc}} \quad$ coefficient taking into account the long-term effects on compressive strength and unfavourable effects resulting from the way the load is applied $\beta_{1} \quad$ concrete strength factor

$\gamma_{\mathrm{c}} \quad$ partial safety factor for concrete

$\varepsilon_{\mathrm{c}} \quad$ concrete compressive strain

$\varepsilon_{\mathrm{cu}} \quad$ ultimate concrete compressive strain

$\varepsilon_{\mathrm{f}} \quad$ tensile strain of longitudinal reinforcement

$\varepsilon_{\mathrm{fu}} \quad$ ultimate tensile strain of longitudinal reinforcement

$\varepsilon_{\mathrm{fw}} \quad$ maximum allowable strain to be developed in the shear reinforcement

$\eta \quad$ factor defining effective strength of concrete

$\lambda$ factor defining effective height of compression zone

$\xi \quad$ ratio of neutral axis depth to the effective depth

$\rho_{\mathrm{f}} \quad$ reinforcement ratio for longitudinal reinforcement

$\rho_{\mathrm{fb}} \quad$ balanced reinforcement ratio for longitudinal reinforcement

$\sigma_{\mathrm{f}} \quad$ tensile stress developed in longitudinal FRP reinforcement

\section{Introduction}

The lack of formal design standards is a significant barrier for the extensive use of fibre-reinforced polymers (FRPs) in reinforced concrete (RC). The first draft design guidelines for FRP RC were published in Japan (JSCE, 1992, 1993, 1997), followed by design recommendations in Europe by the Eurocrete project (Clarke et al., 1996), Canada (CSA, 1996) and the USA (ACI, 1998). The American Concrete Institute (ACI) committee 440 recommendations have been upgraded several times and several European countries have published their own codes or recommendations.

Task group 9.3 of the International Federation for Structural Concrete ( $f i b$ TG 9.3) has already published two technical reports on the use of FRP reinforcement for strengthening applications ( $f i b, 2001 \mathrm{a})$ and as internal concrete reinforcement ( $f i b, 2007)$, and is currently working towards the preparation of a complete set of design guidelines that will combine the latest research efforts and the familiar format of modern Eurocodes.

This paper presents the general philosophy underlying the design 
of $\mathrm{RC}$ elements reinforced with FRPs and discusses the various important design issues dealt with by fib TG 9.3. The mechanical and physical characteristics of FRPs are presented, along with the ways in which these can affect the overall performance of FRP RC members at both serviceability and ultimate limit states, including considerations on the bond between FRPs and concrete and the resulting tension stiffening effect. The behaviour of FRP $\mathrm{RC}$ members in flexure and shear is examined in detail and various design approaches are presented and commented upon.

\section{Design considerations}

FRP reinforcement is linear elastic up to failure and, in general, can develop much greater tensile strength than steel reinforcement, but is less stiff, having an elastic modulus as low as $30000 \mathrm{~N} / \mathrm{mm}^{2}$. As a result, FRPs can lead to RC structures with a very different behaviour from conventional RC. In this section the behaviour of FRP RC members in flexure, shear and bond is examined and various approaches for designing $\mathrm{RC}$ elements with FRP reinforcement are described.

\subsection{Flexure}

It is universally accepted that the basic principles of section analysis also apply in FRP RC. Plane sections are expected to remain plane and no significant bond slip takes place (Duranovic et al., 1997a, 1997b).

For flexural resistance, the amount of reinforcement required depends on the stiffness and strength of the composite material. The FRP strength to stiffness ratio is an order of magnitude greater than that of steel and this has a significant impact on the distribution of stresses along the section. When considering a balanced section, as usually desired in steel RC design, the neutral axis depth for the equivalent FRP RC section is relatively small (Pilakoutas, 2000), as shown in Figure 1.

For such a section this implies that a larger proportion of the cross-section is subjected to tensile stress and that the compressive zone is subjected to a greater strain gradient. Hence, for a similar cross-section as that used for steel RC, much larger deflections and crack widths are to be expected. Furthermore, anchoring of the FRP rebars becomes more difficult due to the high strains developed in the tensile reinforcement.
If all other modes of failure are avoided, flexural capacity is limited either by crushing of the concrete in compression or rupture of the FRP reinforcement in tension. Although both modes are brittle and undesirable, the approach currently adopted is to accept that FRP RC sections will be over-reinforced and that the ultimate failure will be by concrete crushing rather than by reinforcement failure. This issue has been investigated by Pilakoutas et al. (2002) and a new approach for a design philosophy was developed by Neocleous et al., 2005, as presented in Section 3 .

The tensile rupture of FRP reinforcement depends on its type, but also on its bond characteristics. High bond demand around the crack can lead to bond slip, and that would result in violation of the plane-sections assumption and lead to higher deformations. In addition, high surface shear stresses will have a knock down effect on the FRP strength due to development of lateral stresses, leading to lower strength compared with the uniaxial material strength (Imjai et al., 2007a, 2007b).

To predict the mode of failure of FRP RC section, it is necessary to understand the stress developed in the reinforcement and concrete. Figure 2 shows the stress level in the reinforcement at concrete failure, as a function of the percentage amount of reinforcement $\rho_{\mathrm{f}}$ for a particular section (Pilakoutas, 2000). It is shown that the steel RC section becomes over-reinforced at $\rho_{\mathrm{f}}$ around $3 \cdot 2 \%$. Below that $\rho_{\mathrm{f}}$, the section is under-reinforced. In the case of GFRP (glass) and CFRP (carbon) reinforced sections, they both remain over-reinforced for $\rho_{\mathrm{f}}$ above around $0.5 \%$ (assuming strengths of 850 and $1350 \mathrm{MPa}$ for GFRP and CFRP,

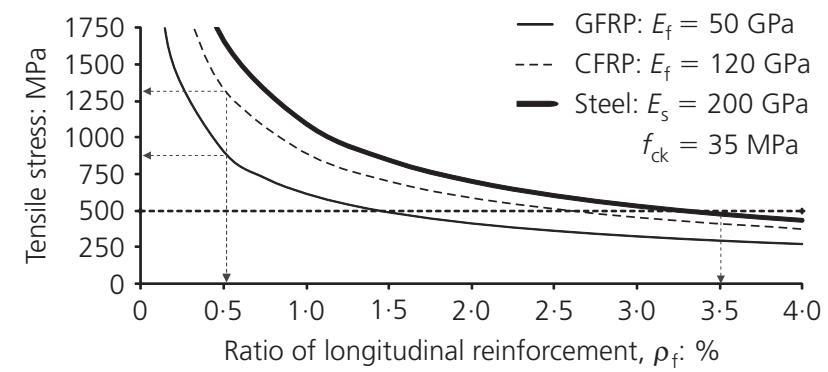

Figure 2. Stress in reinforcement at concrete failure versus percentage amount of reinforcement

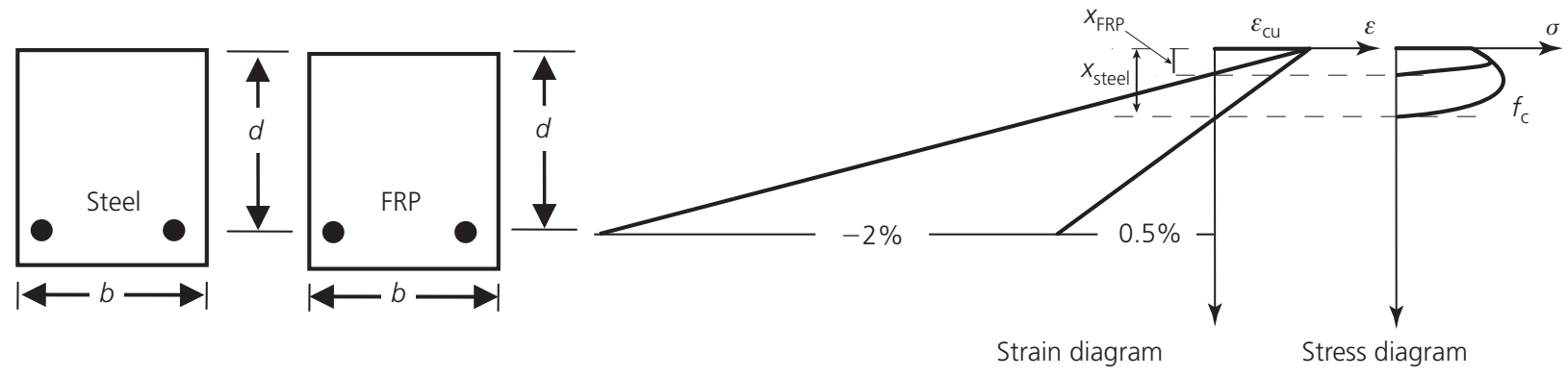

Figure 1. Strain distribution for a GFRP RC section 
respectively). For ratios below $0 \cdot 5 \%$, rupture of the rebar occurs, depending on the strength of the FRP.

It is obvious from Figure 2 that as the reinforcement ratio increases, the stress developed in the FRP bar decreases. When this stress reduces below the strength of steel, larger areas of reinforcement are required to achieve the same moment. This has several implications (Pilakoutas, 2000).

(a) Cost - higher ratios of reinforcement lead to less economic results.

(b) Design philosophy - FRP material partial safety factors become irrelevant if their design strength is not utilised (Neocleous et al., 2005; Pilakoutas et al., 2002).

(c) Short-term deformations - they will be larger if high strains are needed from the FRP.

(d) Long-term deformations - if the stress in the concrete exceeds $0 \cdot 45 f_{c}$, then much larger creep deformations will take place.

From the above discussion, it is clear that FRP over-reinforced concrete sections will be inevitable in most structural applications. Other sources of ductility may be utilised if it is necessary to overcome this problem. Possible solutions include confinement of the concrete compression zone to provide concrete ductility, use of hybrid FRP rebars or a combination of FRP rebars with different characteristics (Burgoyne, 2001; Harris et al., 1998), failing or being mobilised at different strains, to provide pseudoductility. FRP rebars with plastic bond failure may also be used to develop pseudo-plastic behaviour ( $f i b, 2001 \mathrm{~b}$ ), or enhanced structural redundancy may be provided through the addition of sacrificial elements that do not lead to collapse once they fail.

\subsubsection{Amount of longitudinal reinforcement for 'balanced' sections}

Existing design guidelines for FRP (e.g. ACI, 2006; ISIS, 2001) distinguish between the two types of flexural failure (i.e. concrete crushing and FRP rupture) through the reinforcement ratio for 'balanced' sections, $\rho_{\mathrm{fb}}$. This ratio is influenced by the mechanical properties of FRP and concrete and is calculated from expressions derived by considering internal force equilibrium (Equation 1). Similarly, Pilakoutas et al. (2002) proposed Equation 2 for FRP RC beams, which also accounts for the material variability of concrete.

$$
\rho_{\mathrm{fb}}=0.85 \beta_{1} \frac{f_{\mathrm{c}}^{\prime}}{f_{\mathrm{fu}}} \frac{E_{\mathrm{f}} \varepsilon_{\mathrm{cu}}}{E_{\mathrm{f}} \varepsilon_{\mathrm{cu}}+f_{\mathrm{fu}}}\left(\mathrm{N} / \mathrm{mm}^{2}\right)
$$

2. $\rho_{\mathrm{fb}}=\frac{0 \cdot 81\left(f_{\mathrm{ck}}+8\right) \varepsilon_{\mathrm{cu}}}{f_{\mathrm{fk}}\left[\left(f_{\mathrm{fk}} / E_{\mathrm{fk}}\right)+\varepsilon_{\mathrm{cu}}\right]}\left(\mathrm{N} / \mathrm{mm}^{2}\right)$

As expected, Figure 3 shows that the value of $\rho_{\mathrm{fb}}$ increases with

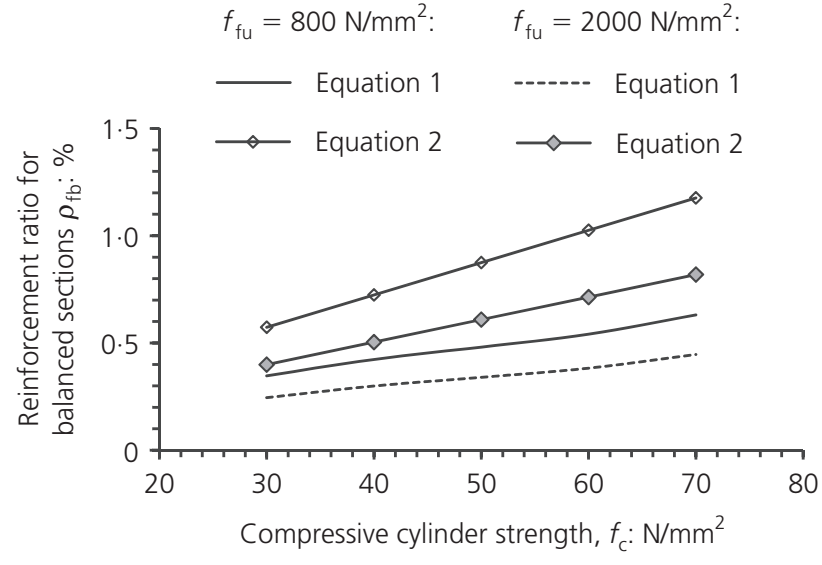

Figure 3. Effect of concrete and FRP properties on $\rho_{\mathrm{fb}}$

concrete compressive strength, while it reduces as the tensile strength of FRP increases. The values given by the expressions proposed by the authors are higher than those predicted by the ACI 440.1R (ACI, 2006).

\subsubsection{Approach for moment resistance of FRP RC elements}

The ultimate moment resistance of FRP RC sections can be evaluated by adopting the framework of Eurocode 2 (CEN, 2004). The compressive strength of FRP reinforcement can be ignored, mainly due to the anisotropic nature of the reinforcement, creep problems and its low contribution to the resistance capacity. However, FRP can be used as compressive reinforcement if concrete confinement is applied or hoop/helical FRP reinforcement is used (Burgoyne, 2001; Ibell et al., 2009).

When the amount of longitudinal FRP reinforcement $\rho_{\mathrm{f}}$ is higher than $\rho_{\mathrm{fb}}$, flexural failure is expected to occur due to concrete crushing, and the ultimate moment resistance $M_{\mathrm{u}}$ can be calculated from

3. $\quad M_{\mathrm{u}}=\eta f_{\mathrm{cd}} b d^{2}(\lambda \xi)\left(1-\frac{\lambda \xi}{2}\right)(\mathrm{Nmm})$

where

4. $f_{\mathrm{cd}}=\frac{\alpha_{\mathrm{cc}} f_{\mathrm{ck}}}{\gamma_{\mathrm{c}}}\left(\mathrm{N} / \mathrm{mm}^{2}\right)$

5. $\alpha_{\mathrm{cc}}=1 \cdot 0$ 


$$
\begin{aligned}
& \left.\begin{array}{l}
\lambda=0 \cdot 8 \\
\eta=1
\end{array}\right\} \text { for } f_{\mathrm{ck}} \leqslant 50 \mathrm{MPa} \\
& \left.\begin{array}{l}
\lambda=0 \cdot 8-\left(\frac{f_{\mathrm{ck}}-50}{400}\right) \\
\eta=1.0-\left(\frac{f_{\mathrm{ck}}-50}{200}\right)
\end{array}\right\} \text { for } 50<f_{\mathrm{ck}} \leqslant 90 \mathrm{MPa}
\end{aligned}
$$$$
7 .
$$

8. $\varepsilon_{\mathrm{f}}=\frac{-\varepsilon_{\mathrm{cu}}+\left[\varepsilon_{\mathrm{cu}}^{2}+\left(4 \eta \alpha_{\mathrm{cc}} f_{\mathrm{ck}} \lambda \varepsilon_{\mathrm{cu}} / \gamma_{\mathrm{c}} \rho_{\mathrm{f}} E_{\mathrm{f}}\right)\right]^{1 / 2}}{2}$

Equation 9 can be used to calculate the stress developed in the FRP reinforcement and, hence, verify that failure due to FRP rupture is avoided

9. $\sigma_{\mathrm{f}}=\varepsilon_{\mathrm{f}} E_{\mathrm{f}}<\frac{f_{\mathrm{fk}}}{\gamma_{\mathrm{f}}}\left(\mathrm{N} / \mathrm{mm}^{2}\right)$

Alternatively, charts such as the one shown in Figure 4 for constant-width FRP RC elements can be used to determine the required reinforcement ratios given the applied moment. The dimensionless parameter $\mu$ is determined by dividing $M$ by $b d^{2} f_{\mathrm{cd}}$. Once the required $\rho_{\mathrm{f}}$ is determined, a check must be made on the reinforcement stress $\sigma_{\mathrm{f}}$ by using charts such as the one shown in Figure 5.

If the amount of reinforcement in an FRP RC section is below $\rho_{\mathrm{fb}}$, the expected type of flexural failure is FRP rupture and, to calculate the ultimate moment of resistance (Equation 10), it is necessary to determine the concrete compressive strain $\varepsilon_{\mathrm{c}}$ at which FRP rupture occurs. This can be achieved through an iterative procedure by solving Equations 11 and 12 .

10. $M_{\mathrm{u}}=\frac{A_{\mathrm{f}} f_{\mathrm{fk}}}{\gamma_{\mathrm{f}}}\left(1-\frac{\xi}{2}\right)(\mathrm{Nmm})$

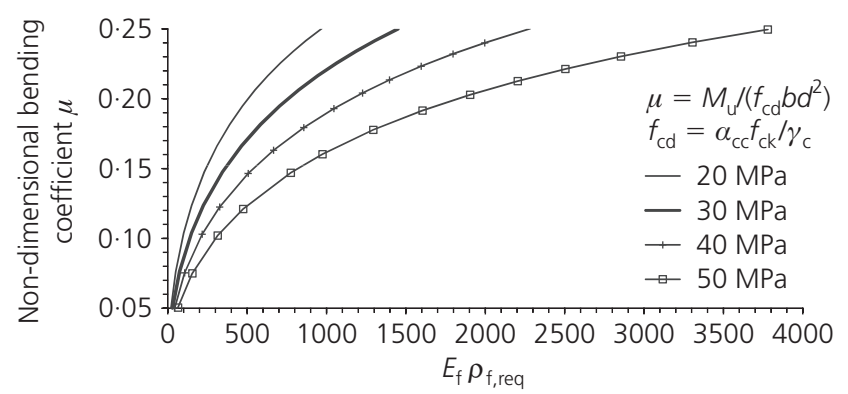

Figure 4. Design chart for flexural capacity of constant-width FRP $\mathrm{RC}$ elements

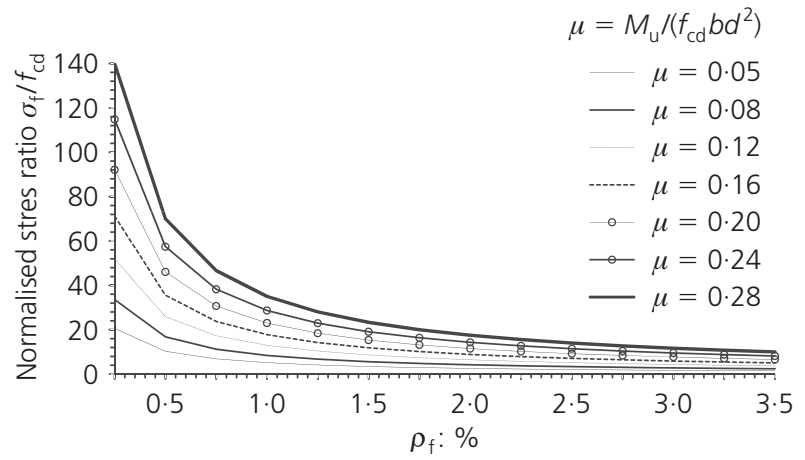

Figure 5. Design chart for tensile stress developed in FRP longitudinal reinforcement

where

11. $\xi=\frac{x}{d}=\frac{\varepsilon_{\mathrm{c}}}{\varepsilon_{\mathrm{fu}}+\varepsilon_{\mathrm{c}}}$

12. $F_{\mathrm{C}}=F_{\mathrm{T}} \rightarrow b d \xi \frac{\int_{0}^{\varepsilon_{\mathrm{c}}} f_{\mathrm{c}} d \varepsilon_{\mathrm{c}}}{\varepsilon_{\mathrm{c}}}=\frac{A_{\mathrm{f}} f_{\mathrm{fk}}}{\gamma_{\mathrm{f}}}(\mathrm{N})$

where $f_{\mathrm{c}}$ is calculated from Equation 13. The values proposed by Eurocode 2 (CEN, 2004) are used for $\varepsilon_{\mathrm{c} 2}$ and $\varepsilon_{\mathrm{cu}}$

$$
f_{\mathrm{c}}=f_{\mathrm{cd}}\left[1-\left(1-\frac{\varepsilon_{\mathrm{c}}}{\varepsilon_{\mathrm{c} 2}}\right)\right] \text { for } 0 \leqslant \varepsilon_{\mathrm{c}} \leqslant \varepsilon_{\mathrm{c} 2} \quad\left(\mathrm{~N} / \mathrm{mm}^{2}\right)
$$

13. $f_{\mathrm{c}}=f_{\mathrm{cd}} \quad$ for $\varepsilon_{\mathrm{c} 2} \leqslant \varepsilon_{\mathrm{c}} \leqslant \varepsilon_{\mathrm{cu} 2}$

To ensure that the ultimate moment resistance is higher than the cracking moment of the RC section, a minimum limit may be applied on the amount of longitudinal reinforcement. Equation 14 can be derived by using the Eurocode 2 approach. It is noted that this equation does not necessarily control cracking.

14. $A_{\mathrm{f}, \min }=0 \cdot 26 \frac{f_{\mathrm{ctm}}}{f_{\mathrm{fk}}} b d \geqslant 0.0013 b d(\mathrm{~mm})$

\subsection{Use of FRP as compression reinforcement}

In most instances, the contribution of FRP bars in compression is low and it can be ignored. However, as stated in Section 2.1.2, concrete confinement and/or the use of helical/tubular FRP reinforcement may allow the use of FRP bars as compression reinforcement (Ibell et al., 2009). More experimental research is required to verify these conclusions. 


\subsection{Serviceability limit states (SLSs)}

There are no fundamental reasons why the principles behind the verification of SLS for FRP RC elements are not similar to those already established in the codes of practice for steel RC elements. However, the actual limits could differ to account for differences in both short- and long-term material properties. The following SLSs for FRP RC members need to be considered

(a) stresses in materials

(b) deflections (short- and long-term)

(c) crack width and spacing.

\subsubsection{Stresses in materials}

The stresses in materials (concrete and FRP) should remain near their elastic limits to avoid long-term deterioration. At this level, stresses can be evaluated using elastic section analysis.

Concrete compressive stresses could be limited to the levels indicated by Eurocode 2 (CEN, 2004), with a maximum $60 \%$ of the characteristic strength, but that may result in uneconomic sections; more work is recommended in this respect.

As far as the reinforcement is concerned, the limitation on FRP stress is more complex and important than for steel due to cracking of the resin and stress corrosion (of glass fibres). fib (2007) presents the levels of stress given by other standards, but has not prescribed new values. The stress levels are also discussed later in Section 3.

\subsubsection{Deflections}

Under similar conditions, in terms of concrete, loading, member dimensions and area of reinforcement, FRP RC members would develop larger deformations than steel reinforced members. This is mainly due to the lower modulus of elasticity of the FRP rebars, but is also influenced to a certain extent by the differences in bond characteristics.

FRP rebars have high tensile strengths and a stress-strain behaviour that is linear up to failure. This leads, under pure bending and beyond the crack formation phase, to almost linear momentcurvature and load-deflection relationships up to failure. Despite this brittle behaviour, FRP elements are capable of achieving large deformations that are comparable to those of steel $\mathrm{RC}$ elements.

The allowable overall deflection depends on the importance of a given structural member, the type of action and the type of structure being considered. To satisfy the SLS of deflection, codes of practice for steel RC specify a minimum thickness by limiting the ratio of the element's effective span to its effective depth. Alternatively, deflections can be calculated and checked to be less than predefined limits that are normally taken as a certain percentage of the effective span of the member. Eurocode 2, for instance, typically limits the design deflections to either span/250 or span/500. Though the span/depth limits are still valid, the span-to-depth ratios need to be redefined.

There are two main approaches to determining deflections of FRP RC. The first involves modifying the ACI equations, which are based on the second moment of area of cracked and uncracked sections, as originally proposed by Branson (1977). Though there are numerous modifications and bond correction factors, these empirical modifications lack a fundamental base and are in general limited in their applications.

On the other hand, the approach used by Eurocode 2 (and Model Code 1990 (CEB-FIP, 1993)) appears to be more fundamental and to be almost directly applicable to FRP RC. Modifications to these equations to account for the use of FRP reinforcement are discussed in detail in fib bulletin 40 (fib, 2007).

\subsubsection{Cracks}

Control of cracking in steel RC members is important for aesthetic purposes, for mitigating the risk of corrosion of steel rebars and for preventing water leakage. When FRP reinforcement is used, corrosion is not the main issue; however, crack widths have to be controlled to satisfy the requirements of appearance and specialised performance. In addition, control of cracking in FRP RC can be utilised as a valuable tool in providing warning of problems in an essentially brittle element.

SLS cracking is normally dealt with by simplified reinforcement detailing rules. Alternatively, the maximum crack width can be calculated and checked not to exceed predefined limits. The predefined limits have been relaxed for FRP, but in general can be around $0.5 \mathrm{~mm}$ (ACI, 2006; fib, 2007).

There are many proposed equations for crack prediction, but the situation is as for deflections. Most equations are empirical and of limited applicability while the Eurocode 2 approach appears to work with minor modifications.

\subsection{Shear}

Shear behaviour of RC members is a complex phenomenon that relies on the development of internal carrying mechanisms, the magnitude and combination of which are still subject to debate. Nevertheless, it has been recognised that the shear resistance of $\mathrm{RC}$ elements is determined mainly by the contribution offered by the uncracked compression zone, aggregate interlock, dowel action and, when provided, shear reinforcement. The development of all of these basic mechanisms, however, depends not only on the characteristics of the concrete but also on the mechanical properties of the reinforcing material and the nature of the interaction between concrete and reinforcement. The larger strains that are induced in the reinforcement of FRP RC elements in general result in larger deflections and wider cracks, and thus affect the development of shear resisting mechanisms. The absence of plastic behaviour in the reinforcement always leads to brittle types of failure and not much dowel strength is expected 
from the more flexible FPR materials. Furthermore, due to the anisotropic properties of FRP reinforcement, FRP links cannot develop their full tensile potential and, as a result, FRP RC elements can fail in shear due to the premature fracture of the shear reinforcement at their bent portions.

Despite the differences underlined above, the typical shear modes of failure that can occur in an FRP RC element, most commonly diagonal tension failure and shear compression failure, initiate and develop in a similar manner to those of conventional RC members. As a result, most of the researchers working in this field have been trying to address the shear problem in a similar way as for steel RC elements and have proposed the use of modification factors for inclusion in existing predictive code equations (Nagasaka et al., 1993).

All of the shear design approaches proposed thus far rely on the fundamental assumption that the shear capacity can be expressed in terms of a concrete contribution and an additional contribution provided by the shear reinforcement. This approach has the perceived advantage that the code committees are more likely to accept such modifications than they are to adopt fundamental changes to the underlying design philosophy, thus enabling a more rapid adoption of FRP reinforcement in the construction industry.

\subsubsection{Shear design approach}

The basic principle underlying existing recommendations for the design of FRP RC structures is that, assuming adequate bond between concrete and reinforcement can be developed, the concrete section experiences forces and strains that are independent of the type of flexural reinforcement utilised. Hence, if a design using FRP maintains the same strain in the longitudinal reinforcement $\left(\varepsilon_{\mathrm{f}}=\varepsilon_{\mathrm{s}}\right)$ and the same design forces are developed $\left(F_{\mathrm{f}}=F_{\mathrm{s}}\right)$, then that design, by definition, will lead to the same safe result as when steel reinforcement is used. In the literature, this is most often referred to as the 'strain approach' (Guadagnini et al., 2003). Based on this assumption (Equation 15), an equivalent area of flexural reinforcement $A_{\mathrm{e}}$ can be determined according to Equation 16

15. $F_{\mathrm{f}}=\varepsilon_{\mathrm{f}} E_{\mathrm{f}} A_{\mathrm{f}}=\varepsilon_{\mathrm{s}} E_{\mathrm{s}} A_{\mathrm{s}}=F_{\mathrm{s}}$

16. $A_{\mathrm{e}}=A_{\mathrm{f}} \frac{E_{\mathrm{f}}}{E_{\mathrm{s}}}$

Most researchers and code developers working in the field adopt this principle of equivalent area of reinforcement, or apply similar correction terms that take into account the different axial rigidity of the flexural reinforcement, in order to evaluate concrete shear resistance.
As far as shear reinforcement is concerned, the amount of FRP required is determined by controlling the maximum strain $\left(\varepsilon_{\mathrm{fw}}\right)$ that can be developed in the shear reinforcement. The limiting values of strain used in initial design recommendations were based on the yielding strain of steel (between 0.2 and $0 \cdot 25 \%$; see Figure 6) (IStructE, 1999), and were imposed primarily to preserve the integrity of the section and guarantee the additive nature of the resisting mechanisms. The maximum stress that can be developed in the shear links $\left(f_{\mathrm{fw}}\right)$ is then simply computed according to Equation 17 and the amount of shear reinforcement is designed according to the well-established truss analogy theory

17. $f_{\mathrm{fw}}=\varepsilon_{\mathrm{fw}} E_{\mathrm{fw}}$

On the basis of experimental evidence, higher allowable strain values (up to $0 \cdot 45 \%$ ) were subsequently proposed (El-Ghandour et al., 1999; Guadagnini et al., 2006) by members of FIB TG 9.3 to capture more adequately the true behaviour of FRP RC elements and have been considered for implementation in next generation design of guidelines. A similar higher value was also included in the latest revisions of the design recommendations produced by the ACI (ACI, 2006).

It should also be mentioned here that, although a variable strut angle approach is the only shear design method used in the current revision of Eurocode 2 (CEN, 2004) for steel RC beams, the simplified, fixed strut angle approach $\left(\theta=45^{\circ}\right)$ is still recommended by the various committees when calculating the shear resistance of RC beams with FRP shear reinforcement, and the additive nature of the shear resistance offered by concrete and shear reinforcement is maintained.

\subsection{Bond of FRP bars}

Bond between concrete and reinforcing bars is the key to developing the composite action of RC elements. Owing to their unique physical and mechanical properties, the bond behaviour of FRP bars to concrete is expected to vary significantly from that of conventional steel bars. In addition, the different local bond behaviour of FRP bars greatly affects the tension stiffening effect

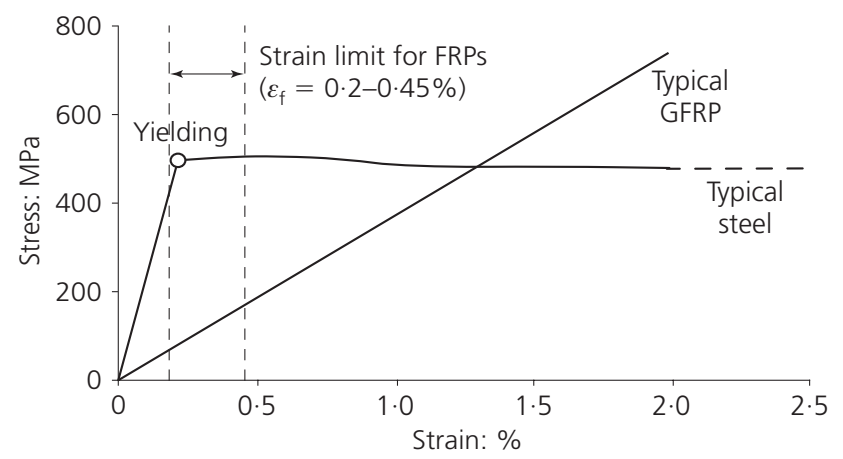

Figure 6. Limiting strain for shear reinforcement adopted by initial and current design recommendations for FRP RC 
of the surrounding concrete and is paramount in determining the structural response of an RC element at a global level, especially at service loads, affecting both cracking and deflections.

While the interaction between deformed steel bars and the surrounding concrete relies mainly on the mechanical interlock of the bar lugs, the bond mechanisms developed in an FRP RC element are controlled predominantly by friction. As a result of the different nature of the fundamental interaction mechanisms, bond failure in steel RC occurs by crushing of the concrete in the vicinity of the lugs, whereas bond failures of FRP RC elements are mainly characterised by partial failure of the concrete surrounding the bars as well as damage within the surface of the FPR bars. Although maximum bond strength values of FRP bars in concrete are generally lower than for steel reinforcement, it has been observed that the more ductile nature of the bond mechanism can lead to a better distribution of bond stresses and, hence, to reduced anchorage lengths.

All of the equations currently available to determine the basic development length of FRP bars adopt existing design equations, which were originally developed for steel reinforcement, and implement a series of modification factors to account for differences in local bond behaviour (ACI, 2006; ISIS, 2001). The modification factors implemented thus far, however, are based on empirical data and there is still a lot of debate among researchers in the field as to the validity and performance of such approaches. The bond behaviour between the large variety of already available types of FRP reinforcement and concrete requires further investigation and a more fundamental approach is needed if optimal structural as well as economic solutions are sought.

\subsection{Detailing}

Although FRPs have been largely adopted in various sectors of the construction industry, their use as internal reinforcement for concrete is currently limited to specific structural elements and does not extend to the whole structure. One of the main reasons for the limited use of FRPs as internal reinforcement is the scarce availability on the market of curved or shaped reinforcing bars that could be used for the detailing of structural connections or to resist internal forces such as shear and torsion.

Furthermore, research studies have shown that the tensile strength of FRP bars can be largely reduced under a combination of tensile and shear stresses (Ehsani et al., 1995; Ishihara et al., 1997). This phenomenon can often become an issue when curved unidirectional composite elements are used as reinforcement in concrete structures (Figure 7) and especially when the fibres are designed to carry high tensile stresses, since premature failure can occur at the corner portion of the composite. In fact, tests by different researchers (Imjai et al., 2007a; Morphy et al., 1997; Yang et al., 2004) have shown that the tensile strength of a bent portion of composite bar can be as low as $40 \%$ of the maximum tensile strength that can be developed in the straight part.

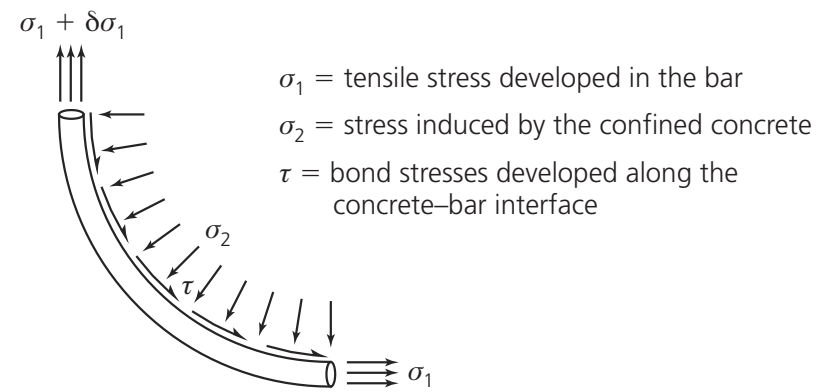

Figure 7. Longitudinal and transversal stress acting on an FRP bent bar embedded in concrete

Although a design model based on macromechanical principles has been recently developed and proposed by Imjai et al. (2007b), the reduction in strength that occurs at the corners of an FRP bar is commonly quantified using empirical models such as that proposed by the Japan Society of Civil Engineers (JSCE, 1997) (Equation 18). In this simple model, the strength of the bent portion $f_{\mathrm{fb}}$ is expressed in terms of the uniaxial tensile strength of the composite $f_{\mathrm{fu}}$ and the bar geometry (i.e. bar diameter $d_{\mathrm{b}}$ and bend radius $r_{\mathrm{b}}$ )

18. $f_{\mathrm{fb}}=\left(0 \cdot 05 \frac{r_{\mathrm{b}}}{d_{\mathrm{b}}}+0 \cdot 3\right) f_{\mathrm{fu}} \leqslant f_{\mathrm{fu}}$

Equation 18 and the relevant strength limit are also adopted in the different design recommendations that have been proposed thus far for FRP RC structures (ACI, 2006; JSCE, 1997).

\section{Design philosophy}

The current approach of developing FRP RC design guidelines by modifying conventional $\mathrm{RC}$ codes of practice may seem reasonable, but it may not be entirely appropriate. The rationale behind this statement is that conventional RC codes of practice assume that the predominant failure mode is always ductile due to yielding of the flexural reinforcement. However, this is not the case for FRP RC design guidelines, which assume that brittle flexural failure would be sustained due to either concrete crushing or rupture of the FRP reinforcement. In addition, existing codes of practice have fundamental structural safety uncertainties that, in conjunction with the change in the type of failure and other design issues relevant to FRP RC, have major implications for the structural design and safety of FRP RC elements (Pilakoutas et al., 2002).

During this work, it was revealed that application of the current partial safety approach (limit state design) does not lead to uniform safety levels and results in RC elements with larger amounts of reinforcement or larger dead to live load ratios being safer. In addition, the resistance capacity margins between the flexural mode of failure and other modes of failure are quite variable and a designer has no reliable means of assessing them. 
Hence, if there is flexural overstrength, codes of practice do not provide information about the failure mode that will actually occur first and at which load level.

Regarding the issues relevant to FPR RC, it was shown that concrete crushing is the most probable type of flexural failure, as the ultimate tensile strength of FRP is rarely attained in normal concrete sections. Furthermore, the use of partial safety factor for longitudinal reinforcement $\left(\gamma_{\text {FRP-L }}\right)$ may not be essential for the design of FRP RC, as long as the flexural failure intended at design is due to concrete crushing.

Another issue arises from the assumption that application of $\gamma_{\text {FRP-L }}$ will always lead to the desired type of flexural failure. This is not always valid, especially for large values of $\gamma_{\text {FRP-L }}$, which are normally expected to lead to flexural failure due to FRP rupture. However, it was highlighted that application of high safety factors would actually lead to concrete crushing and will not necessarily improve the safety of elements.

Additional issues that require further investigation arise when considering the long-term behaviour of FRP RC elements. The application of multiple strength-reduction factors, intended to account for the long-term effects of FRP reinforcement, may have the same effect as large values of $\gamma_{\text {FRP-L }}$ (Neocleous et al., 2005; Pilakoutas et al., 2002) and, thus, may not lead to the mode of failure aimed at the short-term design. The application of multiple strength-reduction factors, as proposed, may even lead to uneconomical designs if it does utilise effectively the strength of FRP reinforcement. It is therefore essential to develop appropriate design provisions that take into account the long-term behaviour of FRP reinforcement. One possible solution is to use the shortterm properties for the limit state design and, subsequently, to verify that (at various time intervals) the applied stress is less than the FRP strength that is available at each time interval.

In view of the above findings, a new design and safety philosophy was developed for FRP RC (Neocleous et al., 2005). The basis of design is still limit state design, but with the main aims being the attainment of a predefined failure mode hierarchy and the satisfaction of target safety levels (e.g. an annual probability of failure of $10^{-6}$ ). The proposed philosophy can be implemented through a framework that enables the determination of appropriate safety factors and forms part of an overall code development process. This approach was adopted because it would enable new materials to be used as they are developed without the need for rewriting the design guide each time. Hence, as a result, the engineer or code committee selects whether concrete crushing, bond failure or shear failure is to be the predominant mode of failure for design purposes but also allows the second failure mode to be determined. This approach will always ensure the correct safety level in a structure without undue conservatism in the second failure mode.

To demonstrate this approach, work at Sheffield University
(Neocleous et al., 2005) has resulted in a proposal for a new set of partial safety factors for use with the Eurocrete FRP bar. For this particular bar, the predominant mode of failure is chosen to be by concrete crushing, hence only relatively modest safety factors are imposed on the reinforcement.

\section{Conclusions}

Although FRP materials have fundamentally different mechanical characteristics than those of steel, the design of FRP RC elements can be based on the same fundamental principles as far as flexural design, shear design, cracking and deflections are concerned. However, a different philosophy of design is needed that addresses the issue of safety at a more fundamental level.

Despite the extraordinary progress made to date in the use of these advanced composite materials, many aspects of their structural behaviour have to be addressed in detail before their full potential can be exploited in new construction.

First-generation design recommendations incorporating the use of FRPs in RC structures are already available and a huge international effort is taking place that will soon produce more advanced guidelines.

\section{Acknowledgements}

The authors wish to acknowledge FIB TG 9.3 and the European Commission for funding the Marie Curie TMR En-Core network.

\section{REFERENCES}

ACl (American Concrete Institute) (1998) ACI 440-98:

Provisional design recommendations for concrete reinforced with FRP bars. ACI, Farmington Hills, MI.

$\mathrm{ACl}$ (2006) ACI 440.1R: Guide for the design and construction of concrete reinforced with FRP bars. ACI, Farmington Hills, MI, pp. 1-45.

Branson DE (1977) Deformation of Concrete Structures, 1st edn. McGraw-Hill, New York.

Burgoyne CJ (2001) Rational use of advanced composites in concrete. Proceedings of the Institution of Civil Engineers, Structures \& Buildings 146(3): 253-262.

CEB-FIP (Comité Euro International du Béton) (1993) CEB-FIP Model Code 1990: Design Code, 1st edn. Thomas Telford, London.

CEN (European Committee For Standardisation) (2004) BS EN 1992-1-1: Eurocode 2: Design of concrete structures. Part 11: General rules and rules for buildings. CEN, Brussels, pp. $1-225$.

Clarke JL, O'Regan DP and Thirugnanenedran C (1996) Eurocrete Project, Modification of Design Rules to Incorporate Non-Ferrous Reinforcement. Sir William Halcrow $\&$ Partners, London.

CSA (Canadian Standards Association) (1996) Canadian Highway Bridge Design Code, Section 16: Fibre Reinforced Structures. CSA, Mississauga, Ont, pp. 1-25.

Duranovic N, Pilakoutas K and Waldron P (1997a) Tests on 
concrete beams reinforced with glass fibre reinforced plastic bars. Proceedings of the 3rd International Symposium on Non-metallic (FRP) Reinforcement for Concrete Structures, Sapporo. Japan Concrete Institute, Tokyo, 2, 479-486.

Duranovic N, Pilakoutas K and Waldron P (1997b) FRP reinforcement for concrete structures: design considerations. Proceedings of the 3rd International Symposium on Nonmetallic (FRP) Reinforcement for Concrete Structures, Sapporo. Japan Concrete Institute, Tokyo, 2, 527-534.

Ehsani MR, Saadatmanesh H and Tao S (1995) Bond of hooked glass fiber reinforced plastic (GFRP) reinforcing bars to concrete. ACI Materials Journal 122(3): 247-257.

El-Ghandour AW, Pilakoutas K and Waldron P (1999) Punching shear behaviour of fiber reinforced polymers reinforced concrete flat slabs: experimental study. ASCE Journal of Composites for Construction 7(3): 258-265.

fib (International Federation for Structural Concrete) (2001a) Externally Bonded FRP Reinforcement for RC Structures. fib Task Group 9.3, Lausanne, fib bulletin 14, pp. 1-138.

fib (2001b) Bond of Reinforcement in Concrete. fib Task Group Bond Models, Lausanne, fib bulletin 10, pp. 1-427.

fib (2007) FRP Reinforcement in RC Structures. fib Task Group 9.3, Lausanne, fib bulletin 40, pp. 1-147.

Guadagnini M, Pilakoutas K and Waldron P (2003) Shear performance of FRP reinforced concrete beams. Journal of Reinforced Plastics \& Composites 22(15): 1389-1407.

Guadagnini M, Pilakoutas K and Waldron P (2006) Shear resistance of FRP RC beams: an experimental study. ASCE Journal of Composites for Construction 10(6): 464-473.

Harris HG, Somboonsong W and Ko FK (1998) New ductile hybrid FRP reinforced bar for concrete structures. ASCE Journal of Composites for Construction 2(1): 28-37.

Ibell T, Darby A and Denton S (2009) Research issues related to the appropriate use of FRP in concrete structures. Construction and Building Materials 23(4): 1521-1528.

Imjai T, Guadagnini M and Pilakoutas K (2007a) Mechanical performance of curved FRP rebars: Part I - experimental study. Proceedings of the 1st Asia-Pacific Conference on FRP in Structures, Hong Kong. The University of Hong Kong, Hong Kong, 1, 333-338.

Imjai T, Guadagnini M and Pilakoutas K (2007b) Analytical study on tensile strength of curved FRP reinforcement. Proceedings of 3rd Central European Congress on Concrete Engineering, Budapest. Budapest University of Technology and Economics, Budapest, 363-368.

Ishihara K, Obara T, Sato Y and Kakuta Y (1997) Evaluation of ultimate strength of FRP rods at bent-up portion. Proceedings of 3rd International Symposium on Non-Metallic (FRP) Reinforcement for Concrete Structures, Sapporo. Japan Concrete Institute, Tokyo, 1, 27-34.

ISIS (Canadian Network of Centres of Excellence on Intelligent Sensing for Innovative Structures) (2001) Design Manual No. 3: Reinforcing Concrete Structures with Fibre Reinforced Polymers. ISIS, Winnipeg, pp. 1-158.

IStructE (Institution of Structural Engineers) (1999) Interim
Guidance on the Design of Reinforced Concrete Structures Using Fibre Composite Reinforcement. IStructE, London, pp. $1-116$.

JSCE (Japan Society of Civil Engineers) (1992) Application of Continuous Fiber Reinforcing Materials to Concrete Structures. JSCE, Tokyo, Concrete library no. 72 (in Japanese).

JSCE (1993) State-of-the-Art Report on Continuous Fiber Reinforcing Materials. JSCE, Tokyo, Concrete engineering series 3.

JSCE (1997) Recommendation for Design and Construction of Concrete Structures using Continuous Fiber Reinforcing Materials. JSCE, Tokyo, Concrete engineering series 23, pp. $1-325$.

Morphy R, Sheata E and Rizkalla S (1997) Bent effect on strength of CFRP stirrups. Proceedings of 3rd International Symposium on Non-Metallic (FRP) Reinforcement for Concrete Structures, Sapporo. Japan Concrete Institute, Tokyo, 2, pp. 19-26.

Nagasaka T, Fukuyama H and Tanigaki M (1993) Shear performance of concrete beams reinforced with FRP stirrups. In Fiber Reinforced-Plastic Reinforcement for Concrete Structures (Nanni A and Dolan CW (eds)). American Concrete Institute, Farmington Hills, MI, SP-138, pp. 789811.

Neocleous K, Pilakoutas K and Guadagnini M (2005) Failuremode-hierarchy based design for reinforced concrete structures. Structural Concrete (fib) 6(1): 23-32.

Pilakoutas K (2000) Composites in concrete construction. In Failure Analysis of Industrial Composite Materials (Gdoutos A, Pilakoutas K and Rodopoulos C (eds)). McGraw-Hill, New York, pp. 449-497.

Pilakoutas K, Neocleous K and Guadagnini M (2002) Design philosophy issues of FRP RC structures. ASCE Journal of Composites for Construction 6(3): 154-161.

Yang X, Wei J, Nanni A and Dharani LR (2004) Shape effect on the performance of carbon fiber reinforced polymer wraps. ASCE Journal of Composites for Construction 8(5): 444-451.

\section{WHAT DO YOU THINK?}

To discuss this paper, please email up to 500 words to the editor at journals@ice.org.uk. Your contribution will be forwarded to the author(s) for a reply and, if considered appropriate by the editorial panel, will be published as a discussion in a future issue of the journal.

Proceedings journals rely entirely on contributions sent in by civil engineering professionals, academics and students. Papers should be $2000-5000$ words long (briefing papers should be 1000-2000 words long), with adequate illustrations and references. You can submit your paper online via www.icevirtuallibrary.com/content/journals, where you will also find detailed author guidelines. 